\title{
Additives Aid Switch to Protect the Photodegradation of Plastics in Outdoor Construction
}

\author{
Salam A. Mohammed ${ }^{1}$, Rahimi M. Yusop ${ }^{2}$, Mohammed Abdulsattar ${ }^{3}$, Rasheed \\ Abed $^{3}$, Dina S. Ahmed ${ }^{4}$, Ahmed Abdulrazaq Ahmed ${ }^{5}$, Ahmed Abdulelah Ahmed ${ }^{6}$, \\ Basheer $\mathrm{Ali}^{5}$, Emad Yousif ${ }^{*} *$
}

\section{Authors affiliations:}

1) Department of Chemical and Petrochemical Engineering, College of Engineering and Architecture, University of Nizwa, Nizwa, Sultanate of Oman.

salam.mohammed@unizwa.edu.om 2) School of Chemical Science and Food Technology, Faculty of Science and Technology, University Kebangsaan Malaysia, 43600 Bangi, Selangor, Malaysia. rahimi@,ukm.edu.my

3) Department of Mechanical Engineering, College of Engineering, Al-Nahrain University, Baghdad, Iraq. m1976sjnr@gmail.com rasheednema@yahoo.com

4) Department of Medical Instrumentation Engineering, AlMansour University College, Baghdad, Iraq. dinasaadi86@gmail.com

5*) Department of Chemistry, College of Science, Al-Nahrain University, Baghdad, Iraq. ahmedahmedalazawi@gmail.com basheerali400@gmail.com emad yousif@hotmail.com

6) Polymer Research Unit, College of Science, Al-Mustansiriyah University, Baghdad, Iraq.

drahmed625@gmail.com

\section{Paper History:}

Received: 26 $6^{\text {th }}$ June 2019

Revised: $20^{\text {th }}$ Sep. 2019

Accepted: 17th Nov. 2019

\section{Introduction}

Polymers are produced annually in huge quantities since they have various interesting industrial and medicinal applications [1]. Schiff bases have various characteristics such as nonlinear optical properties due to the existence of $\mathrm{C}=\mathrm{N}$ moiety [2]. Polymeric materials containing $\mathrm{C}=\mathrm{N}$ unit within the main chain are known as polyazomethines. Polyazomethines have a good thermal resistance [3] and can be used as semiconductors [4], liquid crystals [5], fibers forming [6], electroluminescence materials

\section{Abstract}

Poly(vinyl chloride) photodecomposition films that contains melamine Schiff base (0.5\% by weight) as photostabilizers upon preservation with an ultraviolet light (UV) was investigated. The photodecomposition rate constant was reduced significantly in existence of melamine Schiff base compared to PVC (blank). The Schiff base 1 was found to most effective additive in PVC photostabilization films. Photodecomposition rate content for PVC films containing Schiff base 1 was found to be $5 \times 10^{-3} \mathrm{sec}^{-1}$ compared to $8.7 \times 10^{-3} \mathrm{sec}^{-1}$ for blank film. Ultraviolet radiation aging behaviors of PVC films were studied through leaching test by measuring the degree of migration. The surface morphology of PVC films was inspected by scanning electron microscope.

Keywords: Photodecomposition Rate Constant; Photostabilization; Melamine; Schiff Base; PVC Films; Ice-Rock-Like.

$$
\begin{aligned}
& \text { استخدام مضافات لماية البلاستيك المستخدم في الفنائات الخارجية من } \\
& \text { التكسر الضوئي } \\
& \text { سلام محمد1, رحيمي يوسوب, محمد عبد الستار 3, رشيد عبد 3, دينا أحمد ب, أحمد عبد الرزاق أحمد 5, }
\end{aligned}
$$

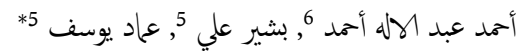

الخلاصة:

تم فص أفلام بولي (كلوريد الفينيل) التي تحتوي على قاعدة شيف الميلامين (0.5 ٪ وزن) كثثبتات

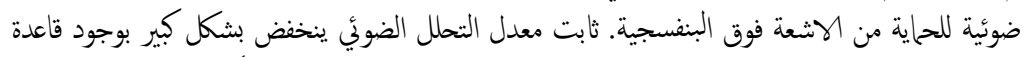

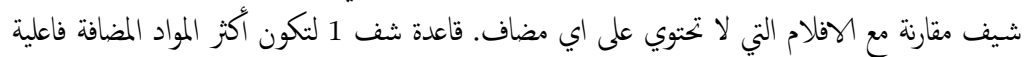

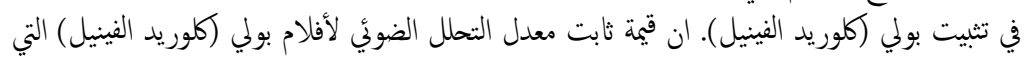

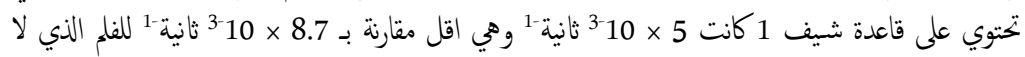

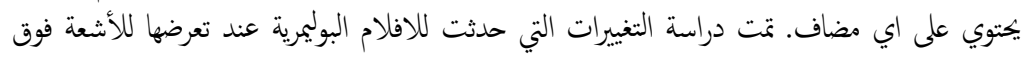

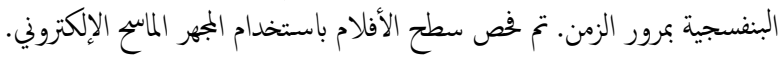

[7] biological agents [8]. Photostabilization for polymer [9]. Poly (vinyl chloride) (PVC) is one of the most produced and wasted polymers widely [10]. It has various outdoor applications [11] such as construction materials [12]. Long term exposure to sunlight and/or high temperature was lead to polymeric photodegradation [13]. As a result, changes in the polymer's physical and mechanical properties occur [14]. The defects or impurities within the PVC polymeric chain are the main reason for dehydrochlorination and/or photo oxidation that

NJES is an open access Journal with ISSN 2521-9154 and eISSN 2521-9162

This work is licensed under a Creative Commons Attribution-NonCommercial 4.0 International License 
lead to formation of unsaturated centers [15]. Therefore, PVC should be protected against harsh weather conditions. PVC Photostabilization can be inspected over the various additives usage. The most common additives are plasticizers [16], aromatics [17], heterocycles [18], Schiff base complexes [19], metal complexes and inorganic salts [19]. Melamine is aromatic, odorless, non-toxic, cheap, and highly stable. It is used in various industrial applications, such as corrosion inhibitors [20]. There are several additives, like agents of ultraviolet light screening, ultraviolet absorber, excited-state quencher, and radical scavenger, have been utilized to modify the antiaging properties of the PVC materials [21]. In this study, we investigated the morphological properties of PVC films containing melamine Schiff bases as antiaging compounds. The photodegradation rate constant $(K d)$, the degree of migration was calculated and the PVC films surface morphology was examined via scanning electron microscopy (SEM). We investigated the photodecomposition rate constant (kd) of PVC polymeric films containing melamine Schiff bases on irradiation with UV light.

\section{Experimental}

\subsection{Materials}

Chemicals have been used (such as solvents and reagents) supplied from Sigma-Aldrich (UK) and been used without further purification. In other hand, a PVC (with 67 as $K$ value, while the polymerization degree $=800$ ) was sourced from Petkim Petrokimya (Turkey).

\subsection{Synthesis of Schiff base 1-5}

Schiff bases 1-5 were synthesized as process reported earlier from the condensation of melamine and equivalents molar of aromatic aldehydes (2hydroxybenzaldehyde,3-hydroxybenzaldehyde,4-

hydroxybenzaldehyde, 4-nitrobenzaldehyde and cinnamaldehyde) in boiling dimethylformamide containing acetic acid (Figure 1) [20]. Schiff bases 15 were obtained in $70-78 \%$ yields as pale-yellow solids.<smiles>Nc1nc(N)nc(N)n1</smiles>

\section{$\mathrm{Ar}=2-\mathrm{HOC}_{6} \mathrm{H}_{4}, 3-\mathrm{HOC}_{6} \mathrm{H}_{4}, 4-\mathrm{HOC}_{6} \mathrm{H}_{4}, 4-\mathrm{NO}_{2} \mathrm{C}_{6} \mathrm{H}_{4}, \mathrm{C}_{6} \mathrm{H}_{5} \mathrm{CH}=\mathrm{CH}$}

Figure (1): Synthesis of Schiff bases 1-5.

\subsection{Films Preparation}

PVC material (5 gm. as final) treated in $100 \mathrm{~mL}$ of tetrahydrofuran to achieve complete dissolving and later the formed mixture was placed in an ultrasonic bath for approximately 30 minutes. The treated sample poured into glass plate to form PVC films after drying the THF residual by keeping the glass plate overnight at $25^{\circ} \mathrm{C}$ [17-21].

\subsection{Characterization}

\subsubsection{Accelerated Testing Technique}

PVC films irradiation was carried out utilizing a standard procedure with an accelerated weathermeter QUV tester (Germany) for $300 \mathrm{~h}$ by supplying a light with intensity of $6.43 \times 10^{-9}$ ein. $\mathrm{dm}^{-3} \cdot \mathrm{s}^{-1}$ and at $\lambda=365 \mathrm{~nm}$.

2.4.2. Photodegradation Rate Constant $(k d)$ of PVC Films by UV Spectrophotometer

160A-Ultraviolet Spectrophotometer (Shimadzu UV-V, Japan) recorded the UV-visible spectra variation for PVC films through light supplying when $\lambda_{\max }=365 \mathrm{~nm}$. Moreover, $k_{d}$ of PVC films (constant of photodecomposition rate was found using below Equation (1).

Where,

$$
\ln (a-x)=\ln a-k_{d} t
$$

$$
a=A_{0}-A_{\infty}, x=A_{0}-A_{t}
$$

$a$ and $x$ are PVC initial concentration and concentration differences at time $t$ during irradiation respectively.

$A_{0}$ and $A_{\infty}=$ the intensity of PVC absorption at $t_{0}$, and $t_{\infty}$ respectively, while $A_{t}=$ the absorption intensity after irradiation time $t$.

Equation (3) was obtained by substituting in Equation (1) by its value in Equation (2).

$\operatorname{In}\left(A_{t}-A_{\infty}\right)=\operatorname{In}\left(A_{0}-A_{\infty}\right)-k_{d} t$

Straight line was extracted by implementing the above correlation giving $k_{d}$ as a slop indicating that the PVC decomposition is first order trend [22].

\subsubsection{Leaching Tests}

The thickness of all the PVC films were around $40 \mu \mathrm{m}$ including the samples which additives have been added to it using Digital Vernier Caliper 2610A micrometer (Germany). As part of the research methodology, the films weights were recorded before and irradiation (at every $50 \mathrm{hrs}$. till time $\infty$ ). The extraction loss was calculated by Equation (4).

Degree of migration $=\left(W_{1}-W_{2}\right) / W_{1} \times 100$

Where $W_{1}$ and $W_{2}=$ initial and final weight of test films respectively [17-21].

\section{Results and Discussion}


Photodecomposition of prepared PVC films before and after adding melamine Schiff bases 1-5 was investigated to study the visibility of the added additives impact. The PVC films $(40 \mu \mathrm{m}$ thickness as has been stated earlier) containing melamine Schiff bases $(0.5 \%$ by weight) irradiated by exposing the samples to UV light. The irradiation had shown clear changes in PVC films and it is expecting that the decomposition took place. The plotting of equation 3 gave straight line with slope represent decomposition rate constant of PVC films. Fig. 2 shows change in $\operatorname{In}\left(A_{t}-A_{\infty}\right)$ against irradiation time $(t)$ for PVC films in the absence of any additives. Figures 3-7 show the changes in $\operatorname{In}\left(A_{t}-A_{\infty}\right)$ against radiation time for PVC films containing melamine Schiff bases additives $(0.5 \%$ by weight) as stabilizers after UV exposing.

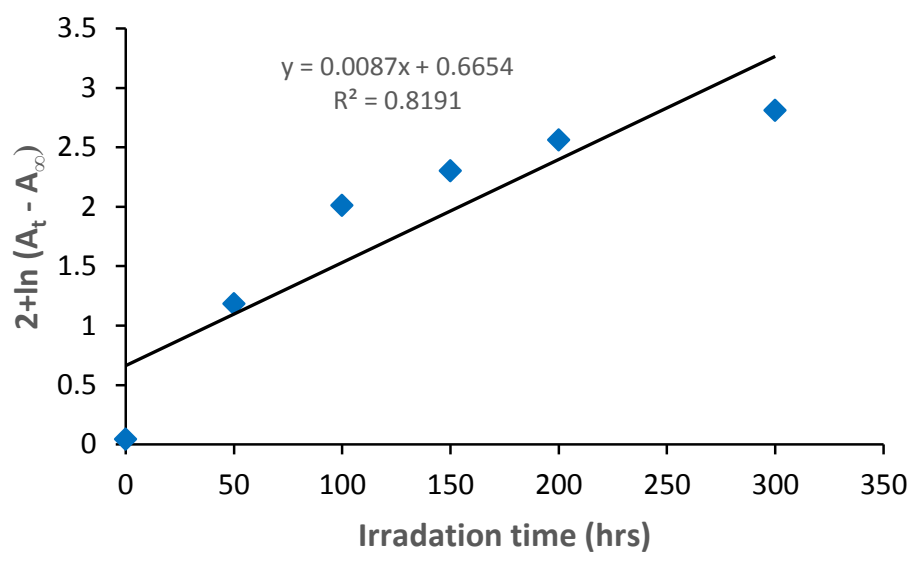

Figure (2): The $\boldsymbol{l n}\left(\boldsymbol{A}_{\boldsymbol{t}}-\boldsymbol{A}_{\infty}\right)$ Changes of PVC (blank) film upon irradiation time.

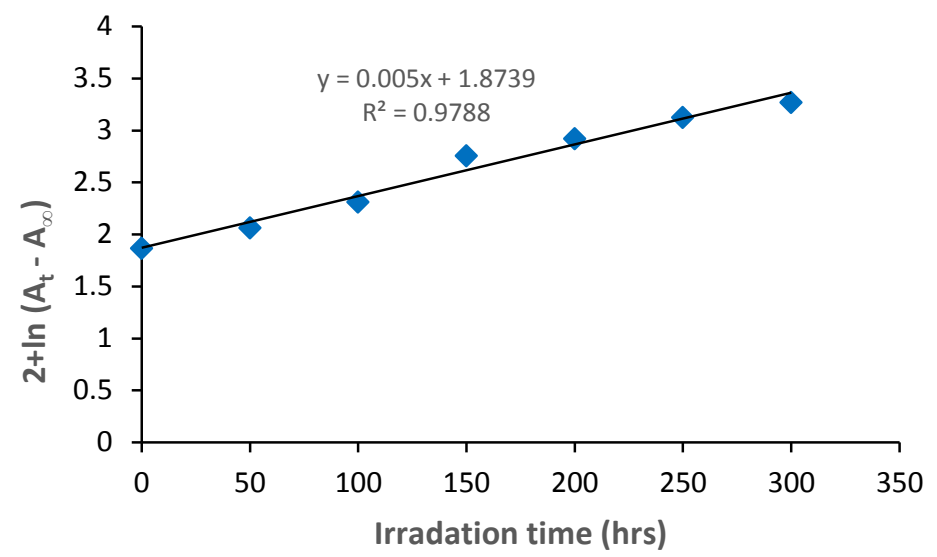

Figure (3): The $\boldsymbol{l n}\left(\boldsymbol{A}_{\boldsymbol{t}}-\boldsymbol{A}_{\infty}\right)$ changes of PVC film containing Schiff base 1 upon irradiation time.

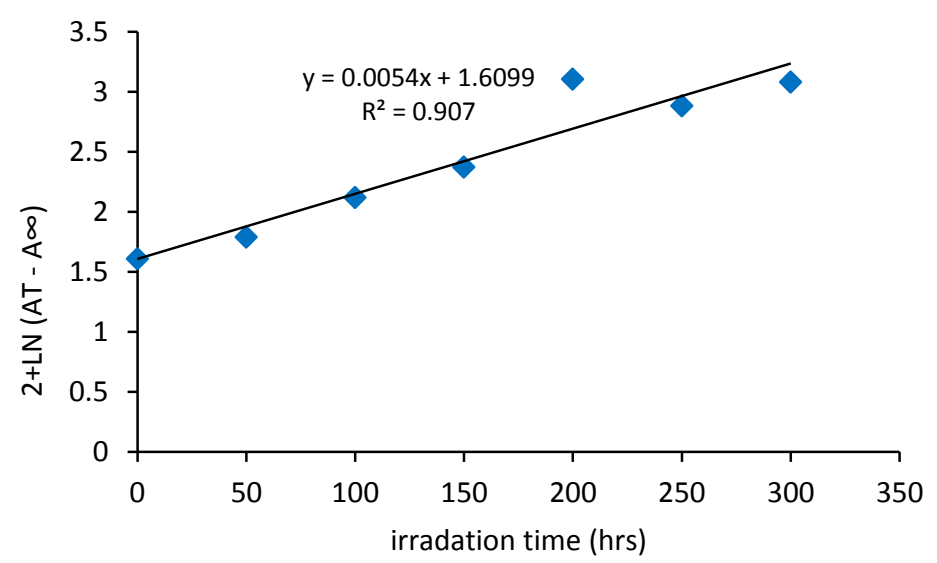

Figure (4): The $\ln \left(A_{t}-A_{\infty}\right)$ changes of PVC film containing Schiff base 2 with times of irradiation. 


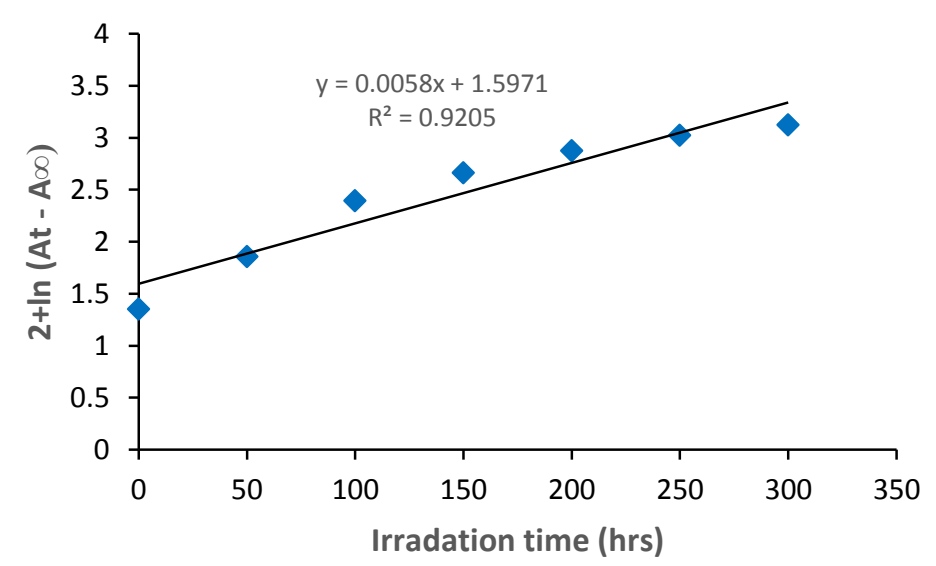

Figure (5): The $\boldsymbol{l n}\left(\boldsymbol{A}_{\boldsymbol{t}}-\boldsymbol{A}_{\infty}\right)$ changes of PVC film containing Schiff base 3 upon irradiation time.

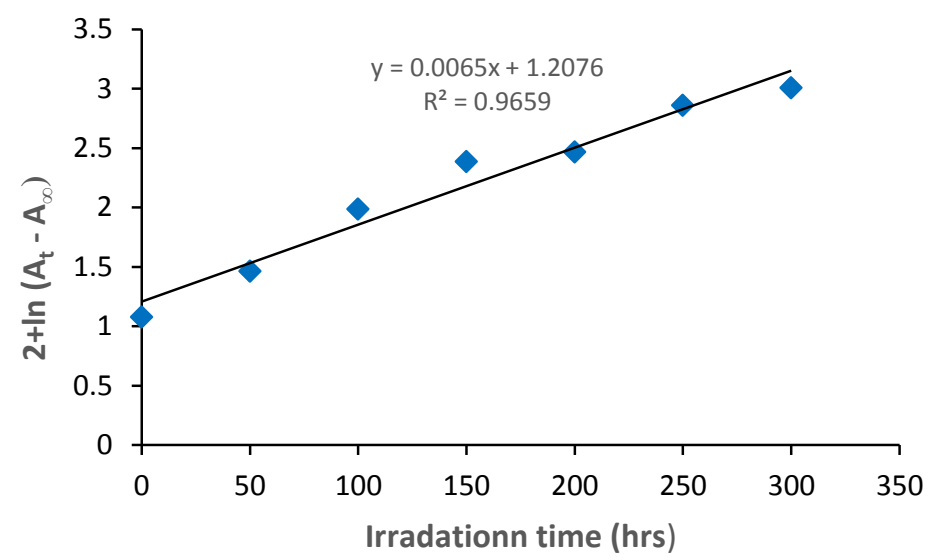

Figure (6): The $\ln \left(\boldsymbol{A}_{\boldsymbol{t}}-\boldsymbol{A}_{\infty}\right)$ Changes of PVC film containing Schiff base 4 with of times irradiation.

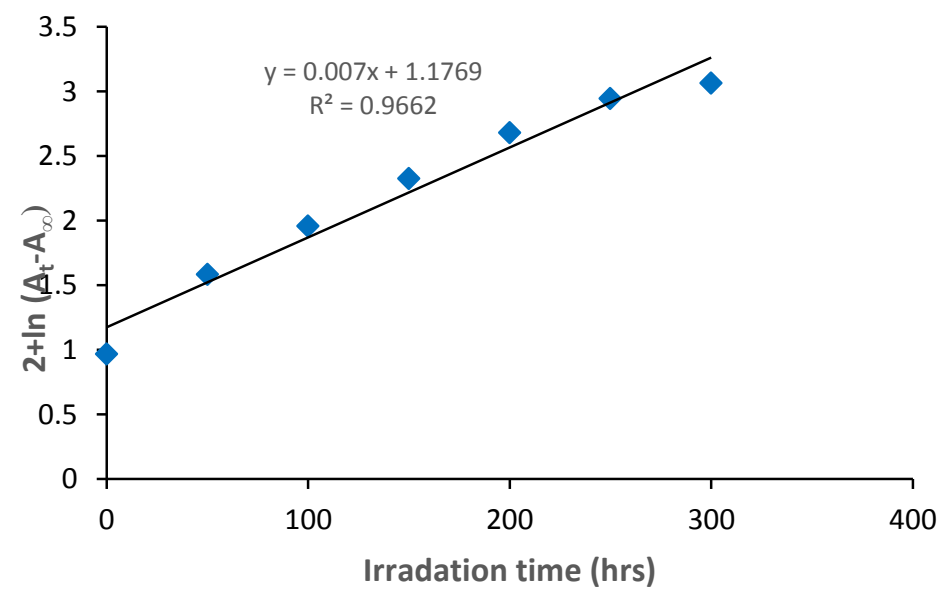

Figure (7): The $\ln \left(A_{t}-A_{\infty}\right)$ changes of PVC film containing Schiff base 5 with times of irradiation.

The rate constant for blank and that containing additives films were listed in Table 1. kd values show the sensitivity of decomposition rate to the presence of melamine Schiff bases and its type [22,23]. As example, $k d$ for PVC (blank) film was high $\left(8.7 \times 10^{-}\right.$ $\left.{ }^{3} \mathrm{sec}^{-1}\right)$, while it dropped significantly $\left(7 \times 10^{-3} \mathrm{sec}^{-1}\right)$ when melamine Schiff bases utilized as additives. PVC photostabilization in the existence of melamine Schiff bases take the order:

$$
1>2>3>4>5 \text {. }
$$

Table (1). kd for PVC films upon UV irradiation (300 h).

\begin{tabular}{|c|c|}
\hline Films & $\boldsymbol{k}_{\boldsymbol{d}}$ value $\mathbf{( s e c}^{-1}$ ) \\
\hline PVC (blank) & $8.7 \times 10^{-3}$ \\
\hline PVC $+\mathbf{1}$ & $5 \times 10^{-3}$ \\
\hline PVC $+\mathbf{2}$ & $5.4 \times 10^{-3}$ \\
\hline PVC $+\mathbf{3}$ & $5.8 \times 10^{-3}$ \\
\hline PVC $+\mathbf{4}$ & $6.5 \times 10^{-3}$ \\
\hline PVC $+\mathbf{5}$ & $7 \times 10^{-3}$ \\
\hline
\end{tabular}


The dehydrochlorination process in PVC films leads to weight loss along with discoloration and production of toxic volatile pollutants [21]. The use of small amounts of the melamine Schiff bases positively influenced the stability of the determined properties during the aging process. Compared to the pure poly (vinyl chloride) subjected to the aging process, the effectiveness of these additives was better than the effectiveness of anti-aging films [17].

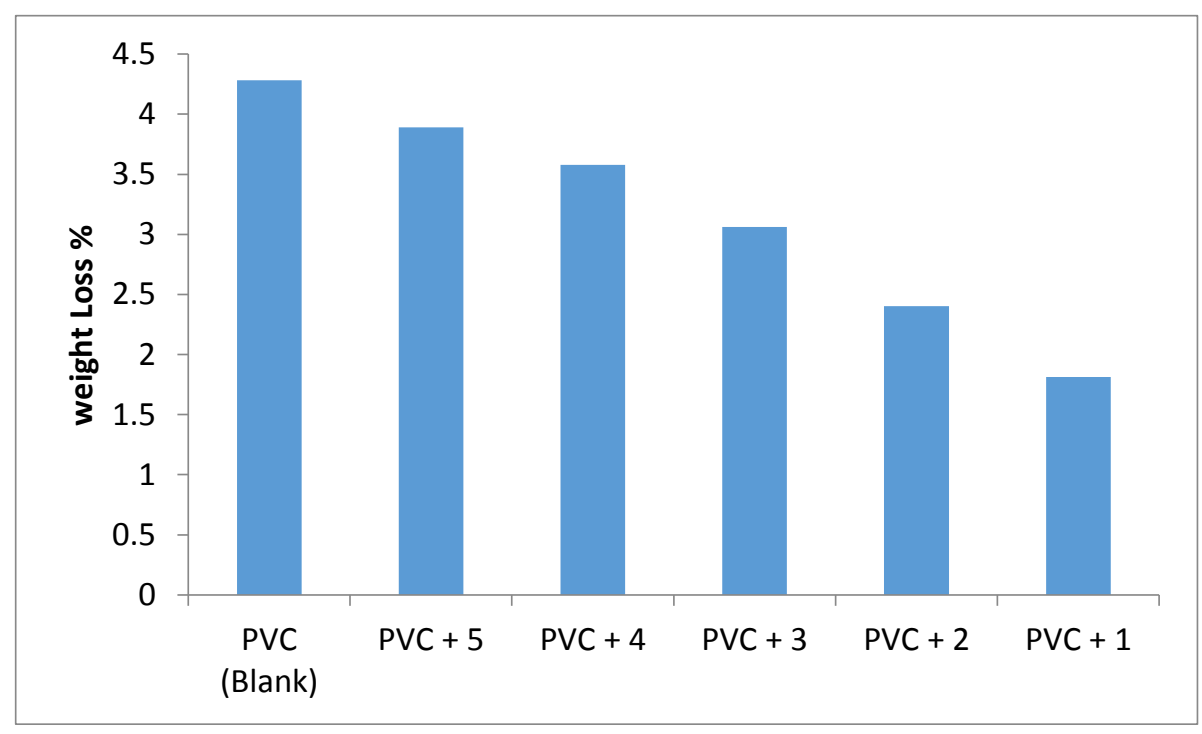

Figure (8): Change in weight loss (\%) of PVC upon irradiation.

Figure 9 displays the SEM micrographs, captured at $15.00 \mathrm{KV}$ voltage, for the irradiated PVC films (neat PVC, PVC/Schiff bases films surface) after irradiation for $300 \mathrm{~h}$. These light spots are accounted as activation points that molded in aging degradation. Many cracks on the surface of neat PVC and PVC/Schiff bases films took place [22]. Those cracks accord due to dehydro-chlorination and oxidation reactions on the surface of the films after been irradiated with UV for 300 hrs. However, the cracks on the surface of PVC/Schiff bases films are barely visible, meanwhile the obvious cracks those samples surfaces are scarcer than that of blank PVC. The cross-linking and evolution of hydrogen chloride and volatile products lead to the formation of an ice-rocklike structure [20]. One of main key of performances enhancement of PVC composites is the dispersion uniformity and good compatibility $[22,24]$.

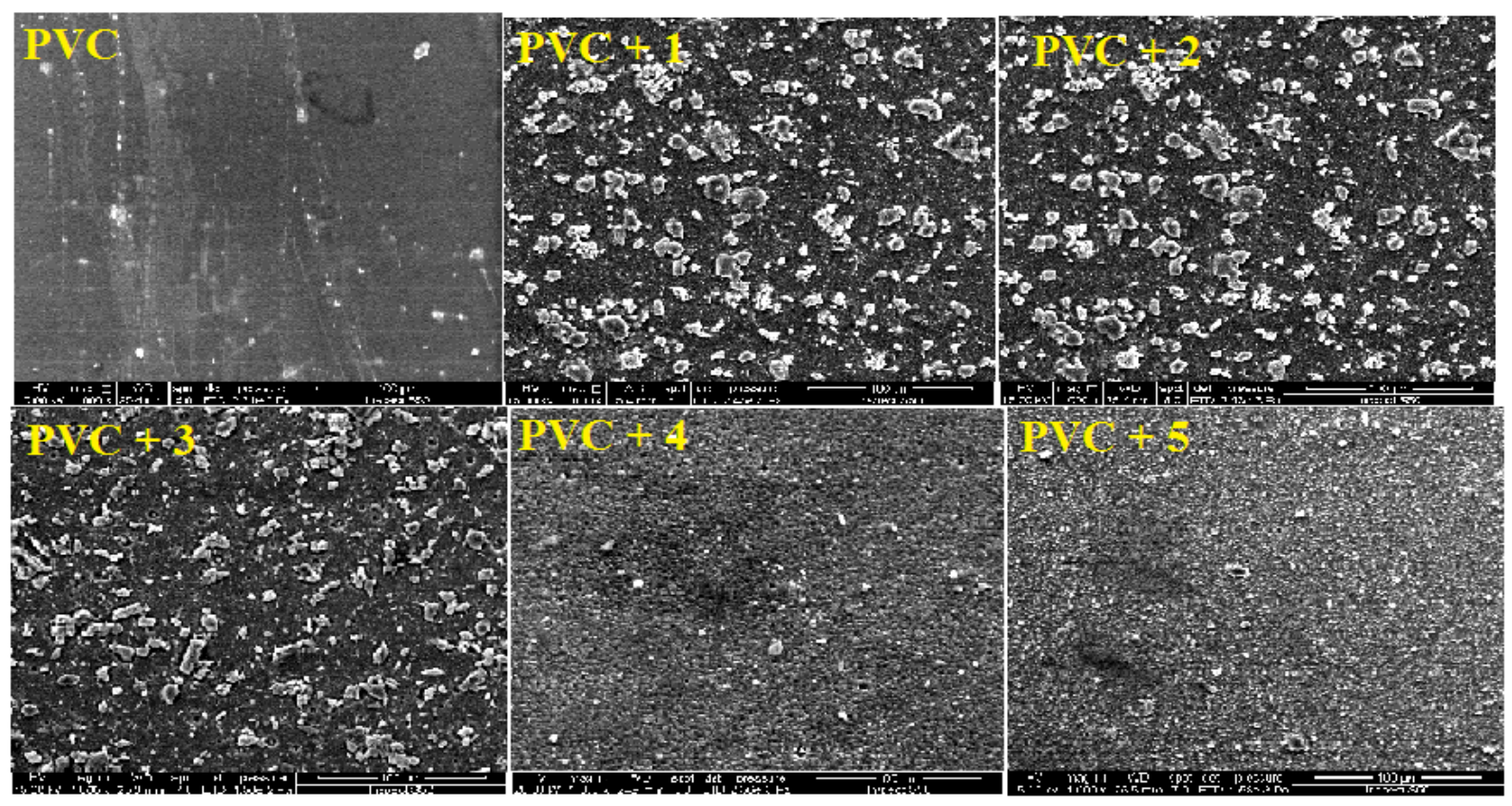

Figure (9): SEM images $(100 \mu \mathrm{m})$ of PVC films after irradiation.

\section{Conclusions}

The photodecomposition rate constants for PVC films containing melamine Schiff bases have been reduced significantly compared to the PVC (blank). kd for PVC films containing melamine Schiff bases were $\left(7 \times 10^{-3}-5 \times 10^{-3}\right) \mathrm{sec}^{-1}$ compared to $8.7 \times 10^{-3} \mathrm{sec}^{-1}$ for PVC (blank) film. Melamine Schiff base 1 was the most effective complex towards the photostabilization of PVC. Clearly, melamine Schiff 
bases have worked as PVC photostabilizers films. No migration was found in leaching tests for PVC films containing melamine Schiff bases. The scanning electron micrograph of PVC doped with additives after long period of irradiation showed piece of icerock resembling structure nature with heterogeneous surface morphology.

\section{References}

[1] E. Carraher, "Giant Molecules: Essential Materials for Everyday Living and Problem Solving", 2nd ed., John Wiley \& Sons, New Jersey: Hoboken, 2003.

[2] A. H. Jawad and M. A. Nawi, "Characterizations of the photocatalytically-oxidized cross-linked chitosan-glutaraldehyde and its application as a sub-layer in the $\mathrm{TiO}_{2} /$ CS-GLA bilayer photocatalyst system," J. Polym. Environ., vol. 20, no. 3, pp. 817-829, 2012.

[3] I. K. Spiliopoulos and J. A. Mikroyannidis, "Soluble, rigid-rod polyamide, polyimides, and polyazomethine with phenyl pendent groups derived from 4, 4 “-diamino-3, 5, 3 ", 5 “-tetraphenyl-pterphenyl," Macromolecules, vol. 29, no. 16, pp. 5313-5319, 1996.

[4] K. I. Aly and A. A. Khalaf, "New polymer syntheses. IX. Synthesis and properties of new conducting polyazomethine polymers containing main chain cycloalkanone and pyridine moieties," J. Appl. Polym. Sci., vol. 77, no. 6, pp. 1218-1229, 2000.

[5] U. Shukla, K. V Rao, and A. K. Rakshit, "Thermotropic liquid-crystalline polymers: Synthesis, characterization, and properties of poly (azomethine esters)," J. Appl.Polym. Sci., vol. 88, no. 1, pp. 153 160, 2003.

[6] P. Cerrada, L. Oriol, M. Piñol, J. L. Serrano, P. J. Alonso, J. A. Puértolas, I. Iribarren and S. Muñoz Guerra, "Influence of hydroxy functionalization and metal cross-linking on fiber properties of liquid-crystalline polyazomethines," Macromolecules, vol. 32, no. 11, pp. 3565-3573, 1999.

[7] S.-H. Jung, T.-W. Lee, Y. C. Kim, D. H. Suh, and H. N. Cho, "Synthesis and characterization of fluorene-based poly (azomethines)," Opt. Mater. (Amst)., vol. 21, no. 1-3, pp. 169-173, 2003.

[8] R. Rasool, S. Hasnain, and N. Nishat, "Metalbased Schiff base polymers: preparation, spectral, thermal and their in vitro biological investigation," Des. Monomers Polym., vol. 17, no. 3, pp. 217-226, 2014.

[9] D. Ghazi, E. Yousif, D. S. Ahmed, H. Thamer, R. Noaman, N. J. Hussien, R. M. Yusop and A. H. Jawad, "Photo-Physical Studies of PVC Mixed with Organotin (IV) Complexes," Al-Nahrain Journal of Science, Vol. 22, , pp. 1-7, 2019.

[10] Z. Huang, A. Ding, H. Guo, G. Lu and X. Huang, "Construction of nontoxic polymeric UVabsorber with great resistance UV- photoaging," Sci. Rep., vol. 6, 2016.

[11] Y. Saeki and T. Emura, "Technical progresses for PVC production," Prog. Polym. Sci., vol. 27, pp. 2055-2131, 2002.
[12] X. Zhang, T. Zhao, H. Pi and S. Guo, "Mechanochemical preparation of a novel polymeric photostabilizer for poly(vinyl chloride)," J. Appl. Polym. Sci., vol. 116, pp. 3079- 3086, 2010.

[13] W. Starnes, "Structural and mechanistic aspects of the thermal degradation of poly(vinyl chloride)," Prog. Polym. Sci., vol. 27, pp. 2133-2170, 2002.

[14] A. G. Hadi, K. Jawad, G. A. El-Hiti, M. H. Alotaibi, A. A. Ahmed, D. S. Ahmed and Emad Yousif, "Photostabilization of Poly(vinyl chloride) by Organotin(IV) Compounds against Photodegradation," Molecules, vol. 24, pp. 3557, 2019.

[15] M. Fahmy, R. Mohamed, A. Mohamed, "Novel antimicrobial organic thermal stabilizer and co-Stabilizer for rigid PVC," Molecules, vol. 17, pp. 7927-7940, 2012

[16] J. Puyou, Z. Meng, H. Lihong, W. Rui, S. Chao, Z. Yonghong, "Cardanol Groups Grafted on Poly(vinyl chloride)—Synthesis, Performance and Plasticization Mechanism," Polymers, vol. 9, pp. 621, 2017.

[17] E. Yousif, R. M. Yusop and D. S. Ahmed, "Photostability of PVC Films by using Safety Synthetic Bio-lubricant as Additives," Malaysian Journal of Chemistry, Vol. 21, pp. 36-42, 2019.

[18] E. Yousif, D. S. Ahmed, A. A. Ahmed, A. S. Hameed, S. H. Muhamed, R. M. Yusop, A. Redwan, S. A. Mohammed, "The effect of high UV radiation exposure environment on the novel PVC polymers," Env. Sci. and Pollu. Res. 2017.

[19] E. Yousif, N. Asaad, D. S. Ahmed, S. A. Mohammed, A. H. Jawad, "A Spectral, Optical, Microscopic Study, Synthesis and Characterization of PVC Films Containing Schiff Base Complexes," Baghdad Science Journal, vol.16, 2019.

[20] G. A. El-Hiti, M. H. Alotaibi, A. A. Ahmed, B. A. Hamad, D. S. Ahmed, A. Ahmed, H. Hashim, E. Yousif, "The Morphology and Performance of Poly(Vinyl Chloride) Containing Melamine Schiff Bases against Ultraviolet Light," Molecules, vol. 24, pp. $803,2019$.

[21] D. S. Ahmed, G. A. El-Hiti, E. Yousif, A. S. Hameed, "Polyphosphates as inhibitors for poly(vinyl chloride) photodegradation," Molecules, vol. 22, pp. 1849, 2017.

[22] D. S. Ahmed, G. A. El-Hiti,H. Hashim, R. Noaman, A. S. Hameed, E. Yousif, "Physical and Morphological Properties of Poly(vinyl chloride) Films upon Irradiation in the Presence of Tetra Schiff Bases as Photostabilizers," Arab J. Phys. Chem. vol. 5, 2018.

[23] E. Yousif, D. S. Ahmed, A. A. Ahmed, A. S. Hameed, R. M. Yusop, A. Redwan, S. A. Mohammed, "Experimental Relationships between Surface Roughness, Irradiation Time and Photodecomposition Rate Constant of PVC Films Doped by Polyphosphates," Science Letters. 2018.

[24] Hashim, G. A. El-Hiti, M. A. Alotaibi, D. S. Ahmed, Y. Emad, "Fabrication of ordered honeycomb porous poly(vinyl chloride) thin film doped with a Schiff base and nickel(II) chloride" Heliyon, vol. 4, 2018. 